\title{
PESTE DES PETITS RUMINANTS: AN OVERVIEW AND A CASE REPORT FROM PAKISTAN
}

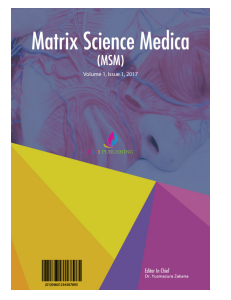

\author{
Mughees Aizaz Alvi ${ }^{1 *}$, Ali Hassan², Qaiser Tanveer ${ }^{2}$, Arva Saleem² ${ }^{2}$ Warda Qamar ${ }^{2}$ \\ ${ }^{1}$ Department of Clinical Medicine and Surgery, University of Agriculture, Faisalabad, Pakistan \\ ${ }^{2}$ Faculty of Veterinary Science, University of Agriculture, Faisalabad, Pakistan \\ *Corresponding author email: mugheesaizazalvi@gmail.com
}

This is an open access article distributed under the Creative Commons Attribution License, which permits unrestricted use, distribution, and reproduction in any medium, provided the original work is properly cited.

\section{ARTICLE DETAILS}

Article history:

Received 12 August 2017

Accepted 12 September 2017

Available online 26 October 2017

\section{Keywords:}

Peste des petits ruminants, sub clinically, heavy economic setbacks, quarantine measures

\section{ABSTRACT}

Peste des petits ruminants (PPR) is an acute or subacute viral disease of goats and sheep characterized by fever, necrotic stomatitis, gastroenteritis, pneumonia, and sometimes death. The virus also affects several wild small ruminant species. Cattle, buffalo, and pigs are only sub clinically infected. People are not at risk. The disease is of heavy economic significance in small ruminant industry and ranks among the top ten diseases affecting small ruminants. Isolation and quarantine measures, slaughtering of positive animals, proper disposal of infected materials, proper disinfection of utensils and other items of flock are crucial for control of PPR. PPR leads to heavy economic setbacks to the farmers. With the aims and objectives to flourish small ruminant farming and maximizing profit, a few key points should be rigorously adopted.

\section{INTRODUCTION}

Peste des Petits Ruminants (PPR) is an infectious, highly contagious viral disease affecting sheep, goats and wild ruminants with high mortality rate. The ailment is transboundary animal disease and is one of the top ten diseases of small ruminants [1]. The other regional. vernacular names of the disease are "Kata", "pseudo rinderpest", "syndrome of stomatitis pneumoenteritis" and "pneumoenteritis complex" [2]. Clinically, the disease is characterized by fever, mucopurulent ocular and nasal discharges, necrotizing and erosive stomatitis, severe enteritis and pneumonia leading to death [3]. The disease is of heavy economic significance in small ruminant industry and ranks among the top ten diseases affecting small ruminants [4]. Economic setbacks in terms of high morbidity, high mortality, dropped production, abortion and trade barrier makes PPR as a disease of global concerns [5].

The etiological agent is a negative sense single stranded enveloped RNA virus belonging to genus Morbillivirus of family Paramyxoviridae. Peste des Petits Ruminants virus (PPRV) is closely related to human measles virus, Rinderpestvirus, canine distemper virus and dolphin distemper virus [6]. There are three proteins associated with the host cell membrane-derived viral envelope viz. matrix protein, fusion protein and HN protein. The pathogen is sensitive to environmental changes and rapid inactivation occurs when exposed to unfavorable conditions outside the host, therefore, close contact is required for the virus to be transmitted from infected to susceptible animal [7].

Primary hosts of the virus are sheep, goats and wild ungulates irrespective of age and sex. However, the disease in cattle and buffalo with poor body condition and stress has also been reported with the signs resembling with that of rinderpest $[8,9,10,11,12]$. The disease mainly effects sheeps and goats but it is more severe in goats where it causes heavy losses [13].

PPRV is shed in all of the body secretions and excretions travel a short distance through aerosol infecting the healthy animals. However, close contact with the infected animal is the most frequent a usual route of transmission. Contamination of feeding and water trough can also serve as additional sources of viral particle transmission.

The clinical signs in ruminanats include pyrexia upto $41^{\circ} \mathrm{C}$, anorexia, dry muzzle, serous ocular and nasal discharges which becomes progressively mucopurulent. Respiratory distress, necrosis and ulceration of buccal mucosa, dehydration and diarrhea due to gastroenteritis appear in advanced stages of the disease. Pregnant female animals may abort. The severity of clinical signs depends upon the age, breed, body condition and innate immunity of the host and virulence of the virus. Concurrent bacterial and parasitic infection can further aggravate the condition [14].
Virus can also be detected through a number of diagnostic techniques including competitive and sandwich ELISA, virus neutralization test, Agar gel immunodiffusion test, haemagglutination test $[15,16,17]$. The competitive ELISA is the most suitable choice suitable choice due to high diagnostic sensitivity and, specificity and reliability [18]. Diagnosis on the basis of genomic detection can be done by RT-PCR, Real time PCR and LAMP Assay [19]. The disease needs to be differentially diagnosed from foot and mouth disease and blue tongue disease due to similarities in clinical signs, therefore, it is necessary to confirm clinical diagnosis through laboratory testing.

\section{PREVENTION AND CONTROL}

Vaccination of susceptible animals is the best option to minimize the risk of occurrence in animal population. Live attenuated vaccine is used to immunize the animals against PPR virus. A number of different vaccines like heterologous vaccines, homologous vaaccines, recombinant marker vaccines, subunit vaccines, multivalent vaccines are available commercially to immunize the susceptible animals. Isolation and quarantine measures, slaughtering of positive animals, proper disposal of infected materials, proper disinfection of utensils and other items of flock are crucial for control of PPR [20,21].

A 7-month old buck of Beetal breed was brought to the Veterinary Teaching Hospital, University of Agriculture, Faisalabad, Pakistan with the presenting complaint of being off-fed, depressed and diarrheoic. History revealed that the animal was suffering from this condition since last day. Through clinical examination revealed that animals was suffering from high grade fever as it's rectal temperature was 106.4F. Other findings included swollen pre-scapular lymph nodes, dehydration $>7 \%$ (sunken eyes and increased skin tenting time), necrotic and erosive oral lesions, mucopurulent ocular and nasal discharge and dyspnea. On the basis of involvement of gastrointestinal system and respiratory system, the disease was diagnosed as PPR.

Supportive therapy plan was instituted and included administration of the following medications:

Lactated ringer $500 \mathrm{ml}$ intravenosuly (Ringer LactaterR, M. S. Enterprises Ltd., Kasur, Pakistan), combination of gentamycin and tylosin $3 \mathrm{ml}$ intramuscularly (GentatyloR, Bio-Pharmachemie-Vitenam), Inj. Aminophylline $7 \mathrm{ml}$ intravenosuly (National M/H, Shanghai, China), Syp. Scour-X (40ml per oral), Drotaverin $2 \mathrm{ml}$ intramuscularly (NospaR, Sanofiaventis Pvt. Ltd.) and Somogel was applied to the oral lesions. This supportive plan was continued for 4 days and the animal recovered completely after 3 days. 


\section{PRESENT STATUS OF PPR IN PAKISTAN}

The disease is endemic in Pakistan and several outbreaks have been reported across the country at varying times of each year. The combined estimates of mean cumulative morbidity and mortality for sheep and goats were estimated $65.37 \%$ and $26.51 \%$ respectively with a case fatality of $40.40 \%$. The species specific mean cumulative morbidity, mortality and case fatality for goats were $68.80 \%, 29.45 \%$ and $42.75 \%$ respectively, while these estimates for sheep were $48.77 \%, 14.98 \%$ and of $26.16 \%$ respectively [22]. In Pakistan, PPR is often diagnosed by clinical signs and symptoms, postmortem examination and laboratory tests including serological,culture and molecular techniques. In recent years various molecular techniques including conventional PCR,real-time PCR has been used for diagnosis of PPR [23, 24, 25, 26]. Mass scale vaccination strategies have been implemented in Pakistan to fight against the menace of PPR. In Pakistan PPR vaccination in sheep and goats is done in the months of MayJune $1 \mathrm{ml}$ through subcutaneous route to provide immunity for 3 years. Tissue culture based live freeze dried PPR Vaccine produced at the centre for Advanced studies in vaccinology and biotechnology, University of Baluchistan, Quetta in 2007 has been used to immunize the animals against PPR infection [27]. Adjuvanted PPR vaccines are also used that induce better immune response in goats as compared to live vaccine. These adjuvanted vaccine provide immunity for a period of 1 year so booster dose after a year is recommended. Mortality in sheep and goats has reduced considerably due to adaption of vaccination program.

\section{CONCLUSION}

PPR leads to heavy economic setbacks to the farmers. With the aims and objectives to flourish small ruminant farming and maximizing profit, a few key points should be rigorously adopted. Of them, isolation of sick animals and constitution of supportive therapy plan, following the quarantine measures of the newly purchased animals before mixing with rest of the herd members and adopting routine vaccination protocols are highly warranted.

\section{REFERENCES}

[1] Zahur, A., Ullah, H., Irshad, A., Latif, R. W., Riasat, M., Jahangir, M., Afzal, S. A., Khan, S. M., Salaria. 2014. Epidemiological Analysis of Peste des Petits Ruminants (PPR) Outbreaks in Pakistan. Journal of Biosciences and Medicines, 2, 18-26.

[2] Parida, S., Muniraju, M., Mahapatra, M., Muthuchelvan, D., Buczkowski, H., Banyard, A.C. 2015. Peste des petits ruminants. Veterinary Microbiology, 181, 90-106.

[3] Diallo, A. 2006. Control of PPR and poverty alleviation, Journal of Veterinary Medicine, 53, 11-13.

[4] Perry, B. D., Randolph, T. F., McDermott, J. J., Sones, K. R., and Thornton, P. K. 2002. Investing in Animal Health Research to Alleviate Poverty. ILRI (International Livestock Research Institute), Nairobi, Kenya.

[5] Kgotele, T., Macha, E. S., Kasnaga, C. J., Kusilaka, L. J. M., Karimuribo, E. D., Van Doorsselaere, J., Wensman, J. J., Munir, M., and Masinzo, G. 2014. Partial genetic characterization pf Peste des petitis Ruminants Virus from Goats in Northern and Eastern Tanzania. Transboundary and emerging diseases, 61, 56-62.

[6] Abubakar, M., Arshed, M. J., Zahur, A. B., Ali, Q., and Banyard, A. C. 2012. Natural infection with peste des petits ruminant's virus: A pre- and postvaccinal assessment following an outbreak scenario. Virus Research, 167, 43-47.

[7] Singh, R. P., Saravanan, P., Sreenivasa, B. P., Singh R. K., and Bandyopadhyay, S. K. 2004. Prevelance and distribution of peste des petitis ruminant's virus infection in small ruminants in India. Revue scientifique et technique (International Office of Epizootics), 23, 807-819.

[8] Abraham, G., Sintayehu, A., Libeau, G., Albina, E., Roger, F., Laekemariam, Y., Abayneh, D., and Awoke, K. M. 2015. Antibody seroprevalences against peste des petits ruminants(PPR) virus in camels, cattle, goats and sheep in Ethiopia, Preventive Veterinary Medicine, 70, 51-57.

[9] Kaukarbayevich, K. Z. 2009. Epizootological analysis of PPR spread on African continent and in Asian countries. African Journal of Agricultural Research, 4, 787-790.

[10] Kihu, S. M., Gachohi, J. M., Gitao, C. G., Bebora, L. C., Njenga, M. J., Wairire, G. G., Maingi, N., and Wahome, R. G. 2013. Analysis of small ruminant's pastoral management practices as risk factors of Peste Des Petitis ruminants spread in Turkana District, Kenya. Research opinions in animal \& veterinary sciences, 3, 303-314.

[11] Kwiatek, O., Ali, Y. H., Saeed, I. K., Khalafalla, A. I., Mohamed, I. O., Obeida, A., Abdelrahman, M. B., Osman, H. M., Taha, K. M., Abbas, Z., ElHarrak, M., Lhor, Y., Diallo, A.., Lancelot, R., Albina, E., and Libeau, G. 2011. Asian lineage of peste des petits ruminant's virus, Africa. Emerging Infectious Diseases journal, 17, 1223-1231.

[12] Diallo, A., Minet, C., Goff, C. I., Berhe, G., Albina, E., Libeau, G., Barrett, T., and Goff, C. 2007. The threat of peste des petits ruminants: progress in vaccine development for disease control. Vaccine, 25, 5591-5597.

[13] Abbas, F., Ullah, A., Awan, M.A., Tariq, M. M., Ali, M., Khan, F. A., Bajwa, M. A., Ahmad, Z., Rashid, N., and Wadood, A. 2012. Production of tissue culture based Peste Des Petitis Ruminants (PPR) vaccine at CASVAB, Quetta, Pakistan. Pakistan Journal of Life and Social Sciences, 10, 80-83.

[14] Munir, M. 2013. Peste des Petitis Rumnants virus, Mononegaviruses of Veterinary importance. Pathobiology and Molecular Diagnosis, 1, 65-98.

[15] Balamurugan, V., Hemadri, D., Gajendragad, M. R., Singh, R. K., and Rahman, H. 2014. Diagnosis and control of peste des petits ruminants: A comprehensive review. Virus Disease, 25, 39-56.

[16] Singh, R. P., Saravanan, P., Sreenivasa, B. P., Singh, R. K., and Bandyopadhyay, S. K. 2004. Prevalence and distribution of peste des petitis ruminants virus infection in small ruminants in India. Revue scientifique et technique (International Office of Epizootics), 23, 807-819.

[17] Nussieba, A. O., Rahman, M. E. A., Ali, A. S., and Fadol, M. A. 2008. Rapid detection of peste des petits ruminants (PPR) virus antigen in Sudan by agar gel precipitation (AGPT) and haemagglutination (HA) tests. Tropical Anim. Health Production, 40, 363-368.

[18] Abbas, F., Ullah, A., Awan, M.A., Tariq, M. M., Ali, M., Khan, F. A., Bajwa, M. A., Ahmad, Z., Rashid, N. and Wadood, A. 2012. Production of tissue culture based Peste Des Petitis Ruminants (PPR) vaccine at CASVAB, Quetta, Pakistan. Pakistan Journal of Life and Social Sciences, 10, 80-83.

[19] Munir, M. 2013. Peste des Petitis Rumnants virus, Mononegaviruses of Veterinary importance. Pathobiology and Molecular Diagnosis, 1, 65-98.

[20] OIE, 2008. World organization for Animal Health, Office Des International Epizootics, (OIE). Manual of standards for diagnostics tests and vaccines,6th Ed.OIE, Paris,1036-1046.

[21] Cosby, S., Kai, C., and Yamanouchi, K. 2005. Immunology of Rinderpest: An immunosuppression but a lifelong vaccine production. Academics press, Elsevier, Amsterdam, The Netherlands.

[22] Zahur, A., Ullah, H., Irshad, A., Latif, R. W., Riasat, M., Jahangir, M., Afzal, S. A., Khan, S. M., Salaria. 2014. Epidemiological Analysis of Peste des Petits Ruminants (PPR) Outbreaks in Pakistan. Journal of Biosciences and Medicines, 2, 18-26.

[23] Abubakar, M., Jamal, S.M., Arshed, M.J., Hussain, M., and Ali, Q. 2008. Incidence of peste des petitis ruminant's virus in sheep and goats as detected by immuno-capture ELISA (IcELISA). Small Ruminants Research, 75, 256-259.

[24] Ali, A., Iftikhar, M., Nadeem, S. M., Subhani, A., and Pohlke, C. 2013. Phylogenetic analysis of peste des petits ruminant's virus isolated from district Gujranwala, Pakistan. Advances in Animal and Veterinary Sciences, $1,32-34$.

[25] Anees, M., Shabbir, M. Z., Muhammad, K., Nazir, J., Shabbir, M. A., Wensman, J. J., Munir, M. 2013. Genetic analysis of peste des petits ruminant's virus from Pakistan. BMC Veterinary Research, 9, 60. doi: 10.1186/1746-6148-9-60.

[26] Durrani, A. Z., Kamal, N., Mehmood, N., and Shakoori, A. R. 2010. Prevalence of peste des petits ruminants (KATA) in sheep and goats of Punjab. Zoological Society Of Pakistan, 42, 211-216.

[27] Abbas, F., Ullah, A., Awan, M.A., Tariq, M. M., Ali, M., Khan, F. A., Bajwa, M. A., Ahmad, Z., Rashid, N., and Wadood, A. 2012. Production of tissue culture based Peste Des Petitis Ruminants (PPR) vaccine at CASVAB, Quetta, Pakistan. Pakistan Journal of Life and Social Sciences, 10, 80-83. 

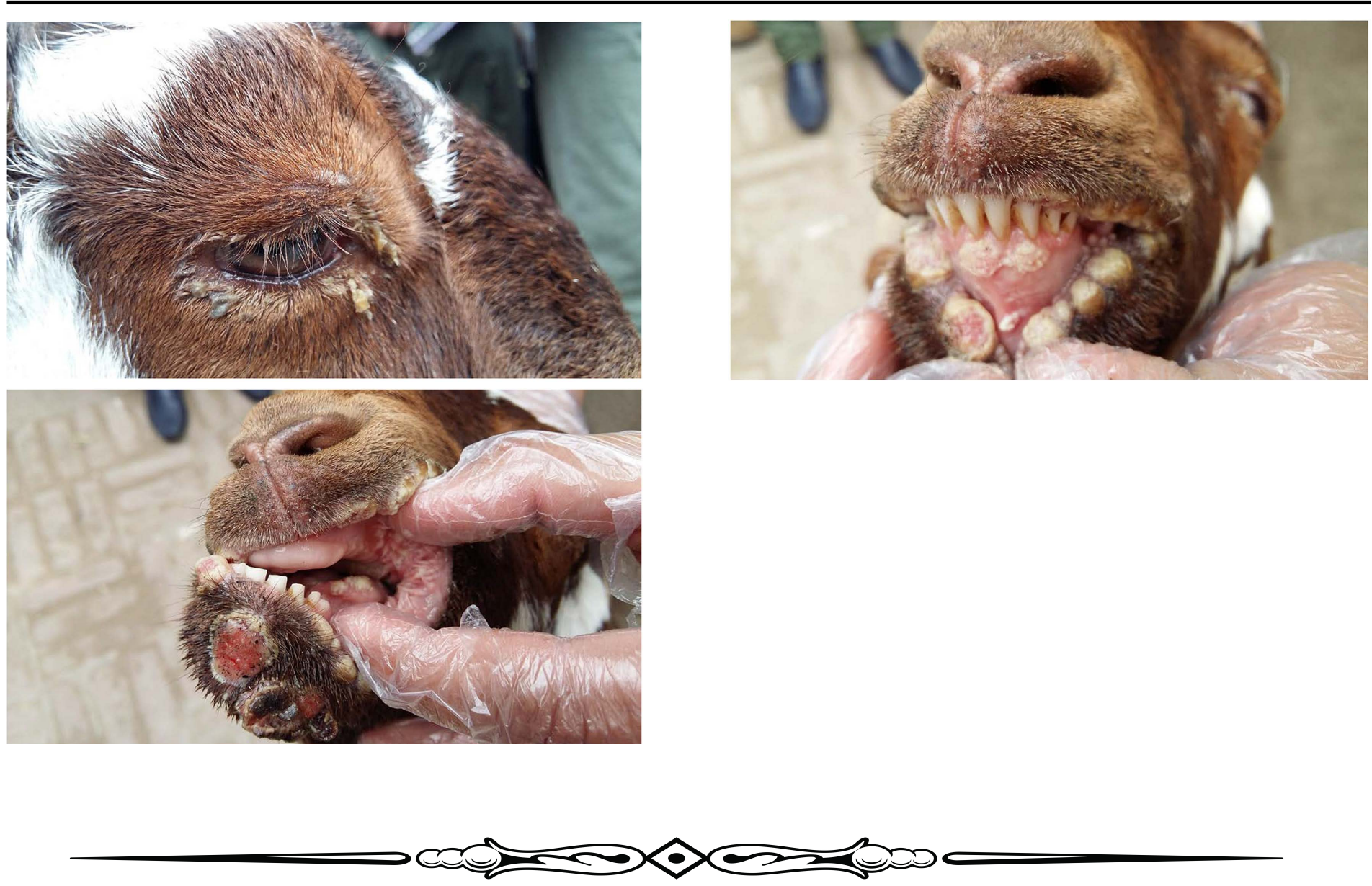